\title{
Improving mechanical and magnetocaloric responses of amorphous melt-extracted Gd- based microwires via nanocrystallization
}

\author{
H. F. Belliveau ${ }^{1}$, Y. Y. Yu ${ }^{1}$, Y. Luo ${ }^{2}$, F. X. Qin ${ }^{3, *}$, H. Wang ${ }^{3}$, H. X. Shen ${ }^{1,4}$, J. F. Sun ${ }^{4}$, \\ S. C. $\mathrm{Yu}^{5, *}, \mathrm{H}$. Srikanth $^{1}$, and M. H. Phan ${ }^{1, *}$ \\ ${ }^{1}$ Department of Physics, University of South Florida, Tampa, Florida 33620, USA \\ ${ }^{2}$ Advanced Composite Center for Innovation and Science, Department of Aerospace \\ Engineering, University of Bristol, University Walk, Bristol, BS8 1TR, UK \\ ${ }^{3}$ Institute for Composites Science Innovation (InCSI), School of Materials Science and \\ Engineering, Zhejiang University, Hangzhou 310027, China \\ ${ }^{4}$ School of Materials Science and Engineering, Harbin Institute of Technology, Harbin 150001, \\ China \\ ${ }^{5}$ Department of Physics, Chungbuk National University, Cheongju 361-763, South Korea
}

\begin{abstract}
We report on the structural, mechanical, and magnetocaloric properties of annealed meltextracted $\mathrm{Gd}_{53} \mathrm{Al}_{24} \mathrm{Co}_{20} \mathrm{Zr}_{3}$ amorphous microwires of $\sim 70 \mu \mathrm{m}$ diameter. During heat treatment small islands of nanocrystallities are generated and isolated in the amorphous region for the wires. The size of the nanocrystallities ranges from $5 \mathrm{~nm}$ to $10 \mathrm{~nm}$. The observed lattice distortion from the nanocrystallities causes changes in the magnetic properties of the wires. The annealing temperature of $100{ }^{\circ} \mathrm{C}$ has the largest strength (1845 MPa) as compared to wires annealed at other temperatures. This is likely to trigger nanophase transformation in the amorphous region and these nanocrystals have been preserved through the increase of annealing
\end{abstract}


temperature. The formulation of the nanocrystalline islands is also verified by the selected-area electron diffraction (SAED). The microwires exhibit a large and reversible magnetocaloric effect (MCE), with the maximum isothermal magnetic entropy change $\left(-\Delta S_{\mathrm{M}}\right)$ and refrigerant capacity $(R C)$ values of $9.5 \mathrm{~J} / \mathrm{kg} \mathrm{K}$ and $689 \mathrm{~J} / \mathrm{kg}$ respectively for the microwire annealed at $100{ }^{\circ} \mathrm{C}$. This $R C$ is about $35 \%, 67 \%$, and $91 \%$ larger than those of bulk $\mathrm{Gd}_{53} \mathrm{Al}_{24} \mathrm{Co}_{20} \mathrm{Zr}_{3}(\sim 509 \mathrm{~J} / \mathrm{kg}), \mathrm{Gd}$ $(\sim 410 \mathrm{~J} / \mathrm{kg})$, and $\mathrm{Gd}_{5} \mathrm{Si}_{2} \mathrm{Ge}_{1.9} \mathrm{Fe}_{0.1}(\sim 360 \mathrm{~J} / \mathrm{kg})$ regardless of their ordering temperatures. These results demonstrate the ability to tune the mechanical and magnetic properties of the microwires by thermal annealing.

PACS: $75.30 . \mathrm{Sg}$

Keywords: Magnetic microwires; magnetocaloric effect; mechanical strength; magnetic refrigeration.

Corresponding authors: faxiangqin@zju.edu.cn (F.X. Qin); scyu@ chungbuk.ac.kr (S.C. Yu); phanm@usf.edu (M.H. Phan)

\section{Introduction}

The magnetocaloric effect (MCE) is a phenomenon where a magnetic material exhibits a temperature or entropy change when subjected to a magnetic field variation [1]. Magnetic refrigeration based on the MCE is considered to be a next-generation cooling technology. Compared to conventional gas compression technology, magnetic refrigeration has advantages such as eliminating the need for energetically inefficient compressors, lack of moving parts, and lack of volatile liquid refrigerants [1-4]. Magnetic refrigerators can be more compactly built when using magnetic solid substances as working materials. Since the heat transfer during the 
refrigeration process is dependent upon the entropy change in the magnetic refrigerant element, a material system exhibiting a large entropy change is highly advantageous to magnetic refrigeration technologies. An entropy change can be induced in magnetic refrigerant materials by either magnetic or structural phase transition, provided that a difference in the magnetization exists between the initial and final phases [2]. In general, it is known that while first-order magnetic transition materials (FOMT) have larger values of magnetic entropy change $\left(\Delta S_{\mathrm{M}}\right)$, they are typically restricted to narrower temperature change, which limits the operating temperature of the magnetic refrigerant. Conversely second-order magnetic transition materials (SOMT) have lower values of $\Delta S_{\mathrm{M}}$ which extends through a broader temperature range [5]. A significant disadvantage of FOMT materials is the large magnetic and thermal hysteretic losses, which are detrimental to the refrigerant capacity (RC). These losses are negligible in SOMT materials. Therefore, the experimental values of $\mathrm{RC}$ have been reported to be greater for SOMT materials than for FOMT ones. The benchmark SOMT material for operating temperatures significantly higher than cryogenic temperatures is gadolinium (Gd). Even after a laborious comparison of existing magnetic refrigerant candidates, Gd still remains the best material. Since Gd is relatively expensive, alloying it with other non-rare-earth elements, such as $\operatorname{Gd}_{5}\left(\operatorname{Si}_{x} G_{1-\mathrm{x}}\right)_{4}$ compounds [1, 6-9], has proven to be useful for improving the MCE while reducing the material cost significantly.

It has been theoretically determined that reducing the dimensions of a magnetic refrigerator can increase the cooling power of the device by increasing the operating frequency. In particular, Kuzmin has shown that shaping magnetic refrigerants in the form of spherical or irregular particles is inefficient, due to their high losses on viscous resistance and demagnetization [10]. Mechanical instability of the refrigerant can result in a significant loss of 
heat throughout due to maldistribution of flow. In this context the use of a bundle of magnetocaloric wires (e.g. Gd wires) has been proposed to be more desirable because this configuration enables higher mechanical stability and lower porosity. In a detailed analysis, Vuarnoz and Kawanami have theoretically shown that a magnetic bed made of arrayed Gd wires yields a greater temperature span between its ends, which results in a higher cooling load at a higher efficiency, as compared to a magnetic bed made of Gd particles [11]. Unlike their bulk counterparts, the use of the wires with increased surface areas also allows for a higher heat transfer between the magnetic refrigerant and surrounding liquid [10,12]. These theoretical studies have opened up new areas for magnetic refrigeration device and material design.

In this respect, we have recently reported the excellent mechanical and magnetocaloric properties of Gd-based amorphous microwires fabricated by a modified precision melt-extraction method $[13,14]$. We have shown that the large magnetic moment of Gd and the presence of the long-range ferromagnetic order result in a large $\Delta S_{\mathrm{M}}$, which, coupled with the broadening of the paramagnetic-ferromagnetic (PM-FM) transition due to structural disorder, contribute to a large $\mathrm{RC}$ [15]. The overall aim of the present work is to improve the mechanical and magnetocaloric properties of these amorphous microwires through introducing an appropriate portion of nanocrystallities into an amorphous matrix. A systematic study of the effects of thermal annealing on the microstructure, mechanical and magnetocaloric properties of melt-extracted $\mathrm{Gd}_{53} \mathrm{Al}_{24} \mathrm{Co}_{20} \mathrm{Zr}_{3}$ amorphous microwires has been performed. We have found that relative to the as-prepared amorphous microwires, the presence of $\sim 5 \mathrm{~nm}$ nanocrystallities formed during low temperature annealing improves both the mechanical and magnetocaloric properties in the annealed microwires. A correlation between the microstructure and mechanical and 
magnetocaloric properties is discussed. Our study paves a new pathway for tailoring the properties of Gd-based microwires for magnetic cooling applications.

\section{Experiment}

Amorphous microwires with a nominal composition $\mathrm{Gd}_{53} \mathrm{Al}_{24} \mathrm{Co}_{20} \mathrm{Zr}_{3}$ have been fabricated using a home-built melt-extraction facility [14]. A brief description of the wire fabrication process is as follows: The ingot with a diameter of $8 \mathrm{~mm}$ was prepared from raw materials Gd (99.9\%), Al (99.99\%), Co (99.99\%) and Zr (99.9\%) crystals in argon atmosphere by arc melting. Melt extraction process was performed using a copper wheel with diameter of $160 \mathrm{~mm}$ and 60 degrees knife edge, with a linear velocity of the wheel rim fixed at $30 \mathrm{~m} / \mathrm{min}$ and a feed rate of the molten material of $90 \mu \mathrm{m} / \mathrm{s}$ [16]. The wire samples obtained under this fabrication condition are amorphous [14].

To further improve the wire properties, annealing was executed at $100{ }^{\circ} \mathrm{C}$ (sample $\mathrm{S} 1$ ), $200{ }^{\circ} \mathrm{C}$ (sample S2), and $300{ }^{\circ} \mathrm{C}$ (sample S3) in a horizontal type quartz tube furnace for $12 \mathrm{~h}$ (the holding time), in comparison with the as-prepared wire (sample S0). The annealing process was conducted in the protective argon atmosphere to prevent severe oxidation and to improve magnetic and magnetocaloric properties of the wires.

The morphology of wires was studied by using a field emission scanning electron microscope (SEM S-4700) at $15 \mathrm{kV}$. The atomic weight percent of the elements present in the amorphous and annealed microwires was investigated by energy dispersive spectroscopy (EDS) using a JEOL JSM-6390LV SEM. The microstructural evolution of the annealed wires was characterized by high-resolution electron transmission microscopy (HRTEM). Magnetic measurements were performed by using a superconducting quantum unit interference device 
(SQUID) from Quantum Design operating over a wide temperature range of 10 - $300 \mathrm{~K}$. Each specimen was prepared in the form of a single wire of $3 \mathrm{~mm}$ length, and magnetic field of up to 5 $\mathrm{T}$ was applied along the axial direction of the wire. Amorphous single microwire was first magnetically measured, and was then taken out for annealing and measured again, in order to compare the magnetic and magnetocaloric properties in the amorphous and annealed states.

\section{Results and Discussion}

\subsection{Morphology and microstructural characterization}

Figure 1 shows the SEM images of wires treated at different temperatures. It can be seen from the inset of Fig. 1(a) that the as-fabricated wires are presented as semi-cylindrical shape with the larger diameter identified to be approximately $71 \mu \mathrm{m}$. The semi-cylindrical shape is a direct result from the fabrication process of the wires that comes from the knife-edge. Additionally, grooves and fluctuations on the outer surface are detected (Fig. 1(a)), indicating inhomogeneous cross-sectional areas along the length of the wires. The diameter of the wires annealed at $100^{\circ} \mathrm{C}$ is slightly less than the as-prepared amorphous wires and contains several grooves and fragments on the surface. As the temperature is increased to 200 and $300^{\circ} \mathrm{C}$, these shallow grooves seem to propagate along the wire's surface. With increasing temperature more fragments can be seen and even peel off from the wires, as shown in Figs. 1(c) and 1(d). These surface defects can be the potential structural-change sites influenced by annealing temperature. However, a clear understanding of the underlying mechanism for the morphological changes in the wires upon annealing remains to be investigated. The atomic weight percent of the elements present in the amorphous and annealed microwires was determined by EDS, and the results are summarized in Table 1. It can be seen in this table that annealing tended to increase Gd amount, while the Co amounts were slightly higher in the 100 and $200{ }^{\circ} \mathrm{C}$ annealed samples but 
significantly lower than in the $300{ }^{\circ} \mathrm{C}$ annealed sample as compared to the as-prepared amorphous wire. These changes in Gd and Co amounts in the annealed wires would also affect the magnetic and magnetocaloric properties.

To examine the microstructural evolution of the annealed wires, we have performed highresolution electron transmission microscopy (HRTEM) studies. Figure 2 shows the HRTEM images of the wire samples annealed at 100,200 and $300^{\circ} \mathrm{C}$. It is shown in Fig. 2(a) that small islands of nanocrystallites (EDS revealed $\mathrm{Gd}(\mathrm{Co})$-richer areas as compared to the amorphous matrix) are generated and isolated in the amorphous region for the wires treated at $100{ }^{\circ} \mathrm{C}$ with the average size of $5 \mathrm{~nm}$. This, as shown below, explains the magnetization and MCE enhancement for this sample. Further increasing the temperature to $200{ }^{\circ} \mathrm{C}$ increases the size of nanocrystallities to approximately $8 \mathrm{~nm}$. The formulation of the nanocrystalline islands is also verified by the selected-area electron diffraction (SAED) in the inset of Fig. 2(b). Figure 2(d) shows the dark field TEM image of $300{ }^{\circ} \mathrm{C}$ annealed wires. It can be seen that nanocrystals are homogeneously distributed in the amorphous region. The size of these nanocrystals increases to a diameter of more than $10 \mathrm{~nm}$ and connected to each other in the amorphous environment (see Fig. 2(c)). The local magnifications (insets of Fig. 2(c)) clearly show nanocrystalline lattice distortions in the interior area of the nanocrystals. The observed lattice distortion would contribute to the overall compromise of the magnetic properties of microwires that will be discussed later.

\subsection{Mechanical properties}

As wires have such fine size, the directly extracted strain data from the Instron machine is not reliable. Also, the normal strain gauge is not applicable to be fixed on the fine wires. Therefore a non-contact technique using video gauge should be adopted to precisely track the 
sample displacement during the tensile test. We have demonstrated that the real tensile strain captured by the video gauge is only $35 \%$ of that obtained from the default software on the tensile machine [14], rendering the video gauge a useful tool in analyzing tensile behavior of tiny wires. In this test, at least five points were set on the wires for monitoring beforehand to accurately capture the tensile strain and five sets of data were collected. The effects of annealing temperature on the mechanical properties of wires were investigated and the stress-strain curves are presented in Fig. 3.

Generally, the tensile strain gradually decreases from $2.1 \%$ of the as-quenched sample to $0.65 \%$ of $300{ }^{\circ} \mathrm{C}$ annealed sample. It has been mentioned above that ridges and furrows on the wire surface were introduced in the fabrication process, which exerts negative influence on mechanical properties. Moreover, with the contribution of annealing temperature, these surface flaws would be easily thermo-activated and propagate along the longitudinal direction in the early elastic deformation stage, subsequently conspiring to the brittle breakage of wires. To minimize this effect and to enhance the ductility of wires, one can think of performing the colddrawn process to wires to eliminate most defects on the surface and consequently homogenize the wire diameters $[16,17]$. In addition, high temperature wire oxidation and structural evolution during annealing might be another factor that conspires to the degraded mechanical performance. It is noted that the $300{ }^{\circ} \mathrm{C}$ annealed sample exhibits a slight tensile ductility of $0.4 \%$, possibly due to a different structure of wires compared to the as-quenched state. The as-prepared amorphous microwire displays the maximum tensile strength of $1700 \mathrm{MPa}$ at the breakage point and a Young's modulus of $85 \mathrm{GPa}$, which is consistent with our previously reported results on Gd-based wires [14]. This result reveals excellent mechanical properties of the microwires since their strength and modulus can be comparable, if not superior to, other engineering counterparts 
such as Ni-based [18], Zr-based alloys [19] or La-based bulk glasses [20]. Of particular note is that, although the tensile strain is compromised to $1.7 \%$ for the sample annealed at $100{ }^{\circ} \mathrm{C}$ compared with as-quenched state, its tensile strength is significantly increased to $2000 \mathrm{MPa}$, thus accordingly elevating the modulus to $120 \mathrm{GPa}$, while further increasing annealing temperature the modulus stabilizes. Hence, it is proposed that the existing annealing temperature of $100{ }^{\circ} \mathrm{C}$ is likely to trigger nanophase transformation on the amorphous region and these nanocrystals have been preserved through the increase of annealing temperature. This result is consistent with analysis in Sec. 3.1. Further increasing the annealing temperature to $300{ }^{\circ} \mathrm{C}$ drastically decreases the tensile strength to $800 \mathrm{MPa}$, which is attributed to the significant growth of the nanocrystallities and sample oxidation in the furnace as evidenced in Fig. 2 (c) and 2(d).

\subsection{Magnetic and magnetocaloric properties}

Figure 4(a) shows the temperature dependence of field-cooled (FC) magnetization $(M-T)$ for the as-prepared amorphous and annealed wire samples measured in a field of $\mu_{0} H=50 \mathrm{mT}$. We have observed that unlike its bulk equivalent, the wire sample exhibits a broad FM-PM transition around $T_{\mathrm{C}}$. The shape of the $M-T$ curve varied with change in the annealing temperature (see Fig. 4(a)). The values of $T_{\mathrm{C}}$ are determined as the minima of the $\mathrm{d} M / \mathrm{d} T$ vs. $T$ curves (see inset of Fig. 4(a)), which are 94, 94, 93, and $92 \mathrm{~K}$ for Sample S0, S1, S2, and S3, respectively.

Figure 4(b) shows the $M-H$ curves taken at $20 \mathrm{~K}$ for the as-prepared amorphous and annealed wire samples. In consistence with the $M-T$ data (Fig. 4(a)), it follows that upon thermal annealing, the saturation magnetization $\left(M_{\mathrm{S}}\right)$ increased for the microwire annealed at $100{ }^{\circ} \mathrm{C}$ but decreased for microwires annealed at higher temperatures (e.g. 200 and $300{ }^{\circ} \mathrm{C}$ ). The increase in $M_{\mathrm{S}}$ for the microwire annealed at $100{ }^{\circ} \mathrm{C}$ is likely related to the improved microstructure of the 
wire due to the formation of $\sim 5 \mathrm{~nm}$ nanocrystallities upon an appropriate annealing. However, the decrease in $M_{\mathrm{S}}$ for microwires annealed at higher temperatures is attributed to the magnetic hardness of the wire caused by high temperature annealing.

In order to evaluate the MCE of the as-prepared and annealed wire samples, we have measured the isothermal magnetization $(M-H)$ curves around $T_{\mathrm{C}}$ and calculated the magnetic entropy change $\left(\Delta S_{\mathrm{M}}\right)$ using Eq. (1).

$$
\Delta S_{M}\left(T, \mu_{0} H\right)=\mu_{0} \int_{0}^{H_{\max }}\left(\frac{\partial M}{\partial T}\right)_{H} d H
$$

where $M$ is the magnetization under a magnetic field $\mu_{0} H$, and $S$ is the magnetic entropy at a given temperature $T[21,22]$.

Figure 5(a,b) shows the $M-H$ isotherms of the as-prepared amorphous and $100{ }^{\circ} \mathrm{C}$ annealed wire samples. Interestingly, large variations in the magnetization around the $T_{C}$ occur at low magnetic fields $(<2 \mathrm{~T})$, indicating a large low-magnetic field induced magnetic entropy change in the microwires sample. This feature is desirable for domestic applications of magnetic refrigerators, where, instead of using expensive superconducting magnets, more economical permanent magnets can be used as a magnetic field source $[1,2]$.

Figure 6(a-d) shows the temperature dependence of $-\Delta S_{M}$ at different magnetic field changes up to $5 \mathrm{~T}$ for the as-prepared amorphous and annealed wire samples. As expected, all the samples exhibit large magnetic entropy changes around the $T_{C}$. The maximum magnetic entropy change $\left(\Delta S_{\mathrm{M}}^{\max }\right)$ has been deduced and listed in Table 2 for all the wire samples. The large values of $\Delta S_{\mathrm{M}}{ }^{\max }$ and $\delta T_{\mathrm{FWHM}}$ (Fig. 6(a)) point to a large refrigerant capacity $(R C)$ or a large relative cooling power $(R C P)$ of the microwires. To confirm this, the $R C$ and $R C P$ of the samples have been determined using the following expressions: 


$$
R C=\int_{T_{\text {cold }}}^{T_{\text {hot }}}-\Delta S_{M}(T) d T
$$

and

$$
R C P=\Delta S_{\mathrm{M}}^{\max } \times \delta T_{\mathrm{FWHM}}
$$

where $T_{\text {hot }}$ and $T_{\text {cold }}$ are the onset and offset temperatures of $\delta T_{\text {FWHM. }}$ FWHM stands for the full width at half maximum of a $\Delta S_{\mathrm{M}}(T)$ curve.

The $R C$ and $R C P$ of the samples have also been calculated and listed in Table 2. As compared to the as-prepared amorphous microwire, thermal annealing has been found to increase $\Delta S_{\mathrm{M}}^{\max }$ for the microwire annealed at $100{ }^{\circ} \mathrm{C}$ while decreasing it for the microwires annealed at higher temperatures $\left(200\right.$ and $\left.300{ }^{\circ} \mathrm{C}\right)$. A similar trend has been observed for the $R C$ or $R C P$ of the samples. It is worth noting in Table 2, that among the samples investigated, the microwire annealed at $100{ }^{\circ} \mathrm{C}$ shows the largest values of $\Delta S_{\mathrm{M}}^{\max }(9.5 \mathrm{~J} / \mathrm{kg} \mathrm{K})$ and $\mathrm{RC}(687 \mathrm{~J} / \mathrm{kg})$ for $\mu_{0} \Delta H=$ $5 \mathrm{~T}$. This value of $R C$ is much greater than that of its bulk counterpart $(R C=509 \mathrm{~J} / \mathrm{kg})[27]$ and other bulk glasses (Table 2). In particular, the $R C$ of the optimally annealed microwire ( 687 $\mathrm{J} / \mathrm{kg})$ is about $67 \%$ and $91 \%$ larger than those of $\mathrm{Gd}(\sim 410 \mathrm{~J} / \mathrm{kg})[3]$ and $\mathrm{Gd}_{5} \mathrm{Si}_{2} \mathrm{Ge}_{1.9} \mathrm{Fe}_{0.1}(\sim 360$ $\mathrm{J} / \mathrm{kg}$ ) [4] regardless of their ordering temperatures.

Relative to their as-prepared amorphous counterparts, the enhancement of the magnetocaloric properties of the annealed microwires comes from the formation of magnetic nanocrystallities due to the competition between the development of short range spatial magnetic ordering and the disordering effect of the random magnetic anisotropy. Annealed at $100{ }^{\circ} \mathrm{C}$, the sample could generate appropriate amount of nanocrystallites to which the amorphous phase was magnetically coupled, giving rise to the $M_{\mathrm{S}}$, while stress relief due to this annealing would also improve the magnetic softness. As a result, the larger values of $\Delta S_{\mathrm{M}}^{\max }$ and $R C$ were achieved in the $100{ }^{\circ} \mathrm{C}$ annealed wire as compared to the as-prepared amorphous wire. When annealed at 
higher temperatures (e.g. 200 and $300{ }^{\circ} \mathrm{C}$ ), however, not only the nanocrystallites grew but its amount increased, thereby depreciating the MCE performance. The considerable decrease of $\Delta S_{\mathrm{M}}^{\max }$ observed for the $300{ }^{\circ} \mathrm{C}$ annealed wire (Table 2) could be attributed to the decreased $M_{\mathrm{S}}$ (Figure 4), arising mainly from the increases in size and density of nanocrystallites, nanocrystalline lattice distortions, as well as the noticeable decrease of Co amount upon the annealing that occurred in this sample (Table 1). Gd-alloys have the most ideal (large $\Delta S_{\mathrm{M}}^{\max }$ and RC) magnetocaloric properties for application in the liquid nitrogen temperature regime.

\section{Conclusions}

In summary, we have shown the enhanced refrigerant capacity in $\mathrm{Gd}_{53} \mathrm{Al}_{24} \mathrm{Co}_{20} \mathrm{Zr}_{3}$ amorphous microwire as compared to its bulk glass. Thermal annealing has been shown to be an effective approach for improving the refrigerant capacity of the microwires. The temperature at which annealing is beneficial for these microwires is relatively low and cheap to accomplish. The enhancement of $R C$ or $R C P$ has been related to the presence of nanocrystallities of $\sim 10 \mathrm{~nm}$ size uniformly embedded in an amorphous matrix. The excellent magnetocaloric properties make the $\mathrm{Gd}_{53} \mathrm{Al}_{24} \mathrm{Co}_{20} \mathrm{Zr}_{3}$ microwires very attractive for active magnetic refrigeration in the nitrogen temperature range. Since these microwires can easily be assembled as laminate structures, they have potential applications as a cooling device for Micro Electro Mechanical Systems (MEMS) and Nano Electro Mechanical Systems (NEMS).

\section{Acknowledgements}

Work at the University of South Florida was supported by the U.S. Department of Energy, Office of Basic Energy Sciences, Division of Materials Sciences and Engineering under Award No. DE-FG02-07ER 46438 (Annealing and magnetocaloric analysis). Work at Harbin

Institute of Technology was supported by the National Natural Science Foundation of China 
under NSFC, Nos. 51371067 (Wire fabrication). Work at Chungbuk National University was supported by the Converging Research Center Program through the Ministry of Science, ICT and Future Planning, Korea under Grant 2015055808. FXQ acknowledges the financial support of NSFC No. 51501162 (Mechanical tests and SEM experiments). H.X. Shen acknowledges the fellowship from China Scholarships Council (CSC, No.201406120138). Y. Luo is under the support of University of Bristol Postgraduate Scholarship and CSC Scholarship. 


\section{References}

[1] V. Franco, J.S. Blá zquez, B. Ingale, and A. Conde, Annu. Rev. Mater. Res. 42 (2012) 305.

[2] B. Ekkes, J. Phys. D Appl. Phys. 38 (2005) R381.

[3] M. H. Phan, S. C.Yu, J. Mag. Mater. 308 (2007) 325.

[4] V. Provenzano, A. J. Shapiro, R. D. Shull, Nature 429 (2004) 853.

[5] V. K. Pecharsky, K. A. Gschneider, and A. O. Tsokol, Rep. Prog. Phys. 68 (2005) 1479.

[6] F. Yuan, J. Du, and B. Shen, Appl. Phys. Lett. 101 (2012) 032405.

[7] X. C. Zhong, P. F. Tang, Z. W. Liu, D. C. Zeng, Z. G. Zheng, H. Y. Yu, W. Q. Qiu, M. Zou, J. Alloy. Comp. 509 (2011) 6889.

[8] M. B. Tang, L. Xia, K. C. Chan, and J. T. Zhao1 J. Appl. Phys. 112 (2012) 113503.

[9] E. Yu žu äk, I. Dincer, and Y. Elerman, Chin. Phys. B 19 (2010) 037502.

[10] M. D. Kuz'min, Appl. Phys. Lett. 90 (2007) 251916.

[11] D. Vuarnoz, T. Kawanami, Appl. Therm. Eng. 37 (2012) 388.

[12] V. V. Khovaylo, V. V. Rodionoval, S. N. Shevyrtalov, and V. Novosad, Phys. Status Solidi B 251 (2014) 2104.

[13] N. S. Bingham, H. Wang, F. Qin, H. X. Peng, J. F. Sun, V. Franco, H. Srikanth, and M. H. Phan, Appl. Phys. Lett. 101 (2012) 102407.

[14] F. X. Qin, N. S. Bingham, H. Wang, H. X. Peng, J. F. Sun, V. Franco, S. C. Yu, H. Srikanth, and M. H. Phan, Acta Mater. 61 (2013) 1284.

[15] A. Biswas, Y. Y. Yu, N. S. Bingham, H. Wang, F. X. Qin, J. F. Sun, S. C. Yu, V. Franco, H. Srikanth, and M. H. Phan, J. of Appl. Phys. 115 (2014) 17A318.

[16] H. Wang, D. W. Xing, X. D. Wang, and J. F. Sun, Metall. Mater. Trans. A 42, (2010) 1103. 
[17] H. Wang, F. X. Qin, D. W. Xing, F. Y. Cao, X. D. Wang, H. X. Peng, and J. F. Sun, Acta Mater. 60 (2012) 5425.

[18] T.Nagase, M. Ueda, and Y. Umakoshi, J. Alloys Compds. 485 (2009) 304.

[19] J. Y. Xing X. Xia, D. Q. Zhao, M. X. Pan, H. Y. Bai, and W. H. Wang, Adv. Eng. Mater. 12 (2010) 1117.

[20] D. Chen, A. Takeuchi, and A. Inoue, Mater. Sci. Eng. A 457 (2007) 226.

[21] T. Hashimoto, T. Numasawa, M Shino, T. Okada, Cryogenics 21 (1981) 11.

[22] A. H. Morrish, The physical properties of magnetism. New York: Wiley (1965).

[23] H. X. Shen, H. Wang, J. S. Liu, F. Y. Cao, F. X. Qin, D. W. Xing, D. M. Chen, Y. F. Liu, J. F. Sun, J. Magn. Magn. Mater. 372 (2014) 23.

[24] A. Biswas, Y. Y. Yu,1 N. S. Bingham, H. Wang, F. X. Qin, J. F. Sun,2 S. C. Yu, V. Franco, H. Srikanth, and M. H. Phan, J. Appl. Phys. 115 (2014) 17A318.

[25] J. D. Dong, A. R. Yan, J. Liu, J. Magn. Magn. Mater. 357 (2014) 73.

[26] Y. F. Liu, X. X. Zhang, D. W. Xing, H. X. Shen, D. M. Chen, J.S. Liu, J.F. Sun, J. Alloy. Comp. 616 (2014) 184.

[27] Q. Luo, D. Q. Zhao, M. X. Pan, and W. H. Wang, Appl. Phys. Lett. 89 (2006) 081914. [28] W. H. Wang, Adv. Mater. 21 (2009) 4524.

[29] J. Du, Q. Zheng, Y. B. Li, Q. Zhang, D. Li, and Z. D. Zhang, J. Appl. Phys. 103 (2008) 023918. 
Table 1. The atomic weight percent of the elements present in the amorphous and annealed microwires determined by energy dispersive spectroscopy (EDS).

\begin{tabular}{|l|c|c|c|c|c|}
\hline Sample & Gd (\%) & Al (\%) & Co (\%) & Zr (\%) & Total (\%) \\
\hline As-prepared & 54.15 & 21.13 & 21.37 & 3.35 & 100 \\
\hline $\mathbf{1 0 0}{ }^{\circ} \mathrm{C}$ & 55.49 & 19.25 & 21.73 & 3.53 & 100 \\
\hline Annealed & & & & & 100 \\
\hline $\mathbf{2 0 0}{ }^{\circ} \mathrm{C}$ & 55.37 & 19.78 & 21.42 & 3.42 & 100 \\
\hline Annealed & & & & & \\
\hline $\mathbf{3 0 0}{ }^{\circ} \mathrm{C}$ & 56.21 & 21.77 & 18.85 & 3.17 & \\
\hline Annealed & & & & & \\
\hline
\end{tabular}


Table 2. Maximum entropy change, $\left|\Delta S_{M}^{\max }\right|$, Curie temperature, $T_{\mathrm{C}}$, refrigerant capacity (RC), and relative cooling power (RCP) for the as-prepared amorphous and annealed wire samples. Values from microwires of other compositions, bulk glasses, $\mathrm{Gd}$ and $\mathrm{Gd}_{5} \mathrm{Si}_{2} \mathrm{Ge}_{1.9} \mathrm{Fe}_{0.1}$ are included for comparison.

\begin{tabular}{|c|c|c|c|c|c|c|}
\hline Microwire & $T_{\mathrm{C}}(\mathrm{K})$ & $\begin{array}{l}\mu_{0} \Delta \mathrm{H} \\
(\mathrm{T})\end{array}$ & $\begin{array}{l}\left|\Delta S_{M}^{\max }\right| \\
(\mathrm{J} / \mathrm{kg} \mathrm{K})\end{array}$ & $\mathrm{RC}(\mathrm{J} / \mathrm{kg})$ & $\mathrm{RCP}(\mathrm{J} / \mathrm{kg})$ & Ref. \\
\hline $\begin{array}{l}\mathrm{Gd}_{53} \mathrm{Al}_{24} \mathrm{Co}_{20} \mathrm{Zr}_{3} \\
\text { (Amorphous) }\end{array}$ & 94 & $\begin{array}{l}5 \\
2\end{array}$ & $\begin{array}{l}8.8 \\
4.3\end{array}$ & $\begin{array}{l}600 \\
220\end{array}$ & $\begin{array}{l}774 \\
296\end{array}$ & This work \\
\hline $\begin{array}{l}\mathrm{Gd}_{53} \mathrm{Al}_{24} \mathrm{Co}_{20} \mathrm{Zr}_{3} \\
\text { (Annealed at } 100{ }^{\circ} \mathrm{C} \text { ) }\end{array}$ & 94 & $\begin{array}{l}5 \\
2\end{array}$ & $\begin{array}{l}9.5 \\
4.7\end{array}$ & $\begin{array}{l}687 \\
285\end{array}$ & $\begin{array}{l}893 \\
348\end{array}$ & This work \\
\hline $\begin{array}{l}\mathrm{Gd}_{53} \mathrm{Al}_{24} \mathrm{Co}_{20} \mathrm{Zr}_{3} \\
\text { (Annealed at } 200{ }^{\circ} \mathrm{C} \text { ) }\end{array}$ & 93 & $\begin{array}{l}5 \\
2\end{array}$ & $\begin{array}{l}8.0 \\
3.8\end{array}$ & $\begin{array}{l}629 \\
243\end{array}$ & $\begin{array}{l}744 \\
307\end{array}$ & This work \\
\hline $\begin{array}{l}\mathrm{Gd}_{53} \mathrm{Al}_{24} \mathrm{Co}_{20} \mathrm{Zr}_{3} \\
\text { (Annealed at } 300{ }^{\circ} \mathrm{C} \text { ) }\end{array}$ & 92 & $\begin{array}{l}5 \\
2\end{array}$ & $\begin{array}{l}5.1 \\
2.4\end{array}$ & $\begin{array}{l}396 \\
144\end{array}$ & $\begin{array}{l}525 \\
184\end{array}$ & This work \\
\hline${ }^{\mathrm{a}} \mathrm{Gd}_{60} \mathrm{Al}_{20} \mathrm{Co}_{20}$ & 109 & 5 & 10.1 & 681 & 915 & {$[23]$} \\
\hline $\mathrm{Gd}_{68} \mathrm{Ni}_{32}$ & 122 & 3 & 4.5 & 322 & 405 & [24] \\
\hline${ }^{\mathrm{a}} \mathrm{LaFe}_{11.6} \mathrm{Si}_{1.4}$ & 195 & 2 & 9.0 & N/A & 45 & [25] \\
\hline
\end{tabular}




\begin{tabular}{|l|l|l|l|l|l|l|}
\hline $\mathrm{Ni}_{48} \mathrm{Mn}_{26} \mathrm{Ga}_{19.5} \mathrm{Fe}_{6.5}$ & 361 & 5 & 4.7 & $\mathrm{~N} / \mathrm{A}$ & 18 & {$[26]$} \\
\hline $\begin{array}{l}\mathrm{Gd}_{53} \mathrm{Al}_{24} \mathrm{Co}_{20} \mathrm{Zr}_{3} \\
(\mathrm{Bulk})\end{array}$ & 93 & 5 & 9.4 & 509 & $\mathrm{~N} / \mathrm{A}$ & {$[27]$} \\
\hline $\begin{array}{l}\mathrm{Gd}_{48} \mathrm{Al}_{25} \mathrm{Co}_{20} \mathrm{Zr}_{3} \mathrm{Er}_{4} \\
(\mathrm{Bulk})\end{array}$ & 84 & 5 & 9.4 & 647 & N/A & {$[28]$} \\
\hline $\begin{array}{l}\mathrm{Gd}_{55} \mathrm{Co}_{20} \mathrm{Al}_{25} \\
(\mathrm{Bulk})\end{array}$ & 103 & 5 & 8.8 & 541 & N/A & {$[29]$} \\
\hline $\begin{array}{l}\mathrm{Gd}_{55} \mathrm{Co}_{25} \mathrm{Ni}_{20} \\
(\mathrm{Bulk})\end{array}$ & 78 & 5 & 8.0 & 640 & N/A & {$[29]$} \\
\hline $\begin{array}{l}\mathrm{Gd}_{(\mathrm{bulk})}{ }^{\mathrm{b}} \\
\mathrm{Gd}_{5} \mathrm{Si}_{2} \mathrm{Ge}_{19} \mathrm{Fe}_{0.1} \\
(\mathrm{Bulk})^{\mathrm{b}}\end{array}$ & 305 & 5 & 7.0 & 360 & N/A & {$[4]$} \\
\hline
\end{tabular}

${ }^{\mathrm{a}}$ Multiple wires were used for magnetocaloric measurements. ${ }^{\mathrm{b}}$ Crystalline structure. 


\section{Figure captions}

Figure 1: Scanning electron microscopy (SEM) images of melt-extracted (a) as-prepared amorphous wires and wires annealed at, respectively, (b) $100{ }^{\circ} \mathrm{C}$, (c) $200{ }^{\circ} \mathrm{C}$ and (d) $300{ }^{\circ} \mathrm{C}$. Inset shows a cross-sectional area SEM image for the as-prepared amorphous wire.

Figure 2: The HRTEM images of metallic wires annealed at (a) $100^{\circ} \mathrm{C}$, (b) $200^{\circ} \mathrm{C}$, and (c) $300^{\circ} \mathrm{C}$, respectively. The insets of (a) and (b) are the selected area electron diffraction (SAED) pattern of the noted regions. The insets of (c) are inverse transform selected area (IFFT) patterns of the noted regions. The dark field image of $300^{\circ} \mathrm{C}$ annealed wires is display in (d).

Figure 3: Tensile stress-strain curves of the metallic wires annealed at different temperature, the inset is the annealing temperature dependence of maximum tensile strength and Young's modulus of wires.

Figure 4: Temperature dependence of the magnetization for the as-prepared and annealed wire samples. Inset shows the $\mathrm{dM} / \mathrm{dT}$ vs. $\mathrm{T}$ curves, whose minima correspond to the Curie temperatures of the samples.

Figure 5: Isothermal magnetization curves for (a) the as-prepared wire sample, and the wire samples annealed at (b) $100^{\circ} \mathrm{C}$, (b) $200^{\circ} \mathrm{C}$, and (d) $300^{\circ} \mathrm{C}$.

Figure 6: Temperature dependence of the magnetic entropy change $-\Delta S_{M}$ for (a) the as-prepared wire sample, and the wire samples annealed at (b) $100^{\circ} \mathrm{C}$, (b) $200^{\circ} \mathrm{C}$, and (d) $300^{\circ} \mathrm{C}$. 
$50 \mu \mathrm{m}$

(c)

Fluctuations

$71 \mu \mathrm{m}$ y

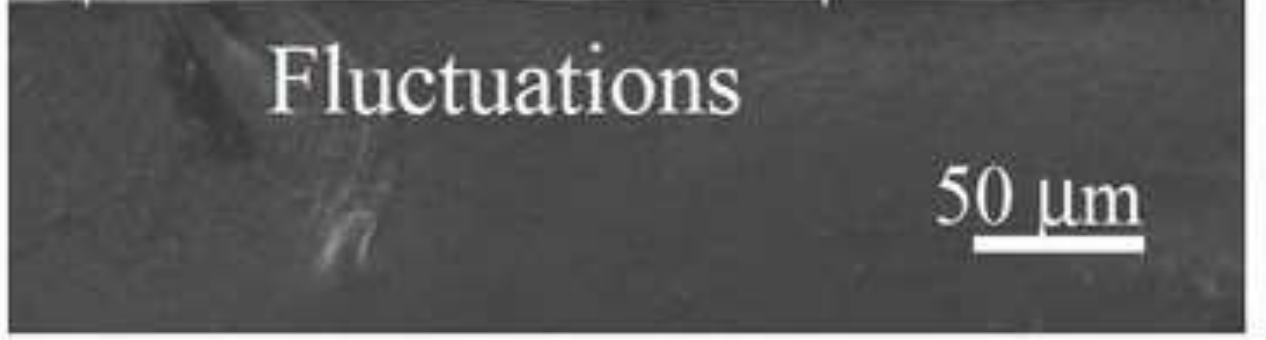

(b)

cracks $^{4}$

\section{$70 \mathrm{~mm}$}

$20 \mu \mathrm{m}$

(d)

Fragments

$62 \mu \mathrm{m}$
$54 \mathrm{pm}$

2

20 


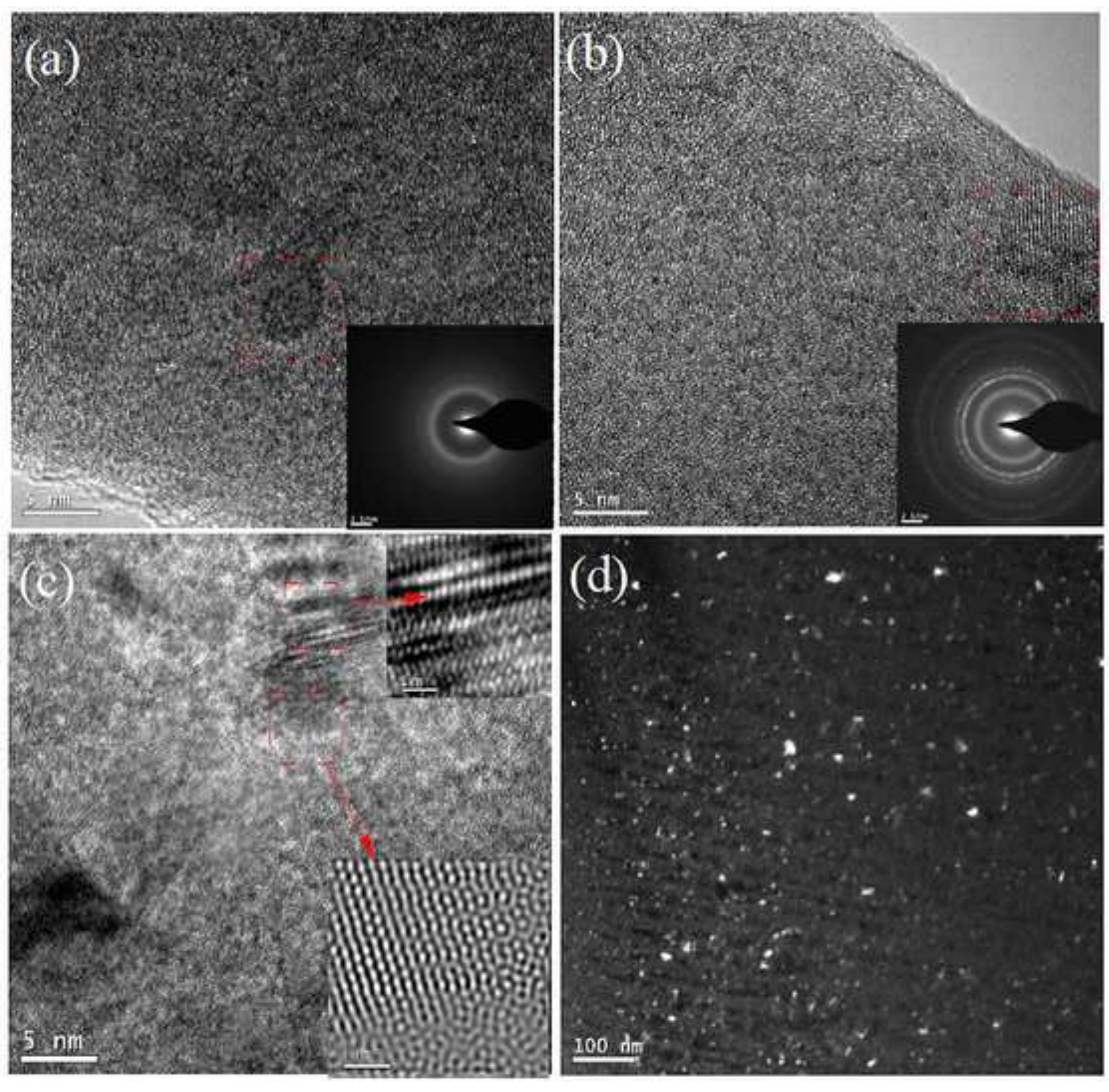

(a)
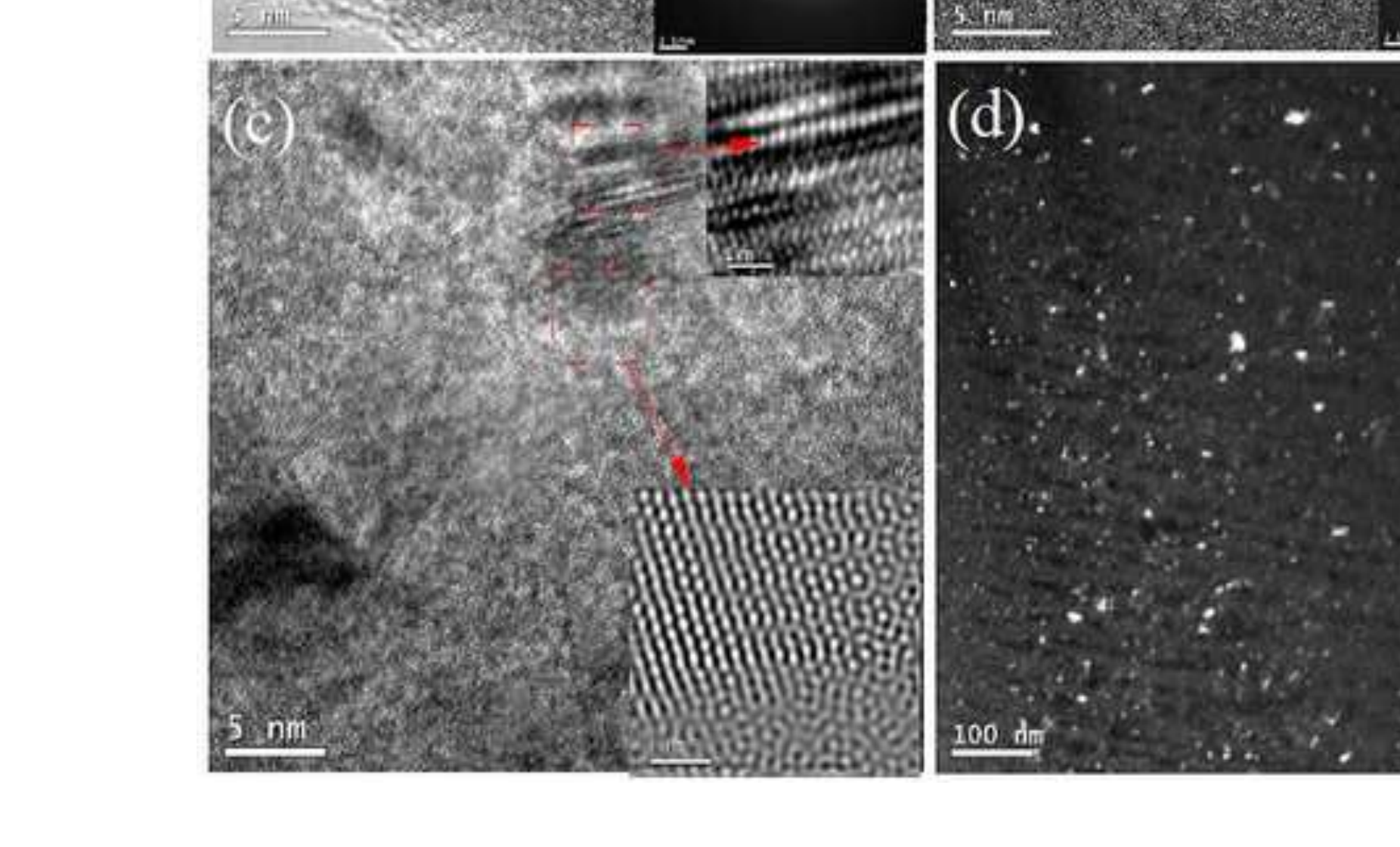


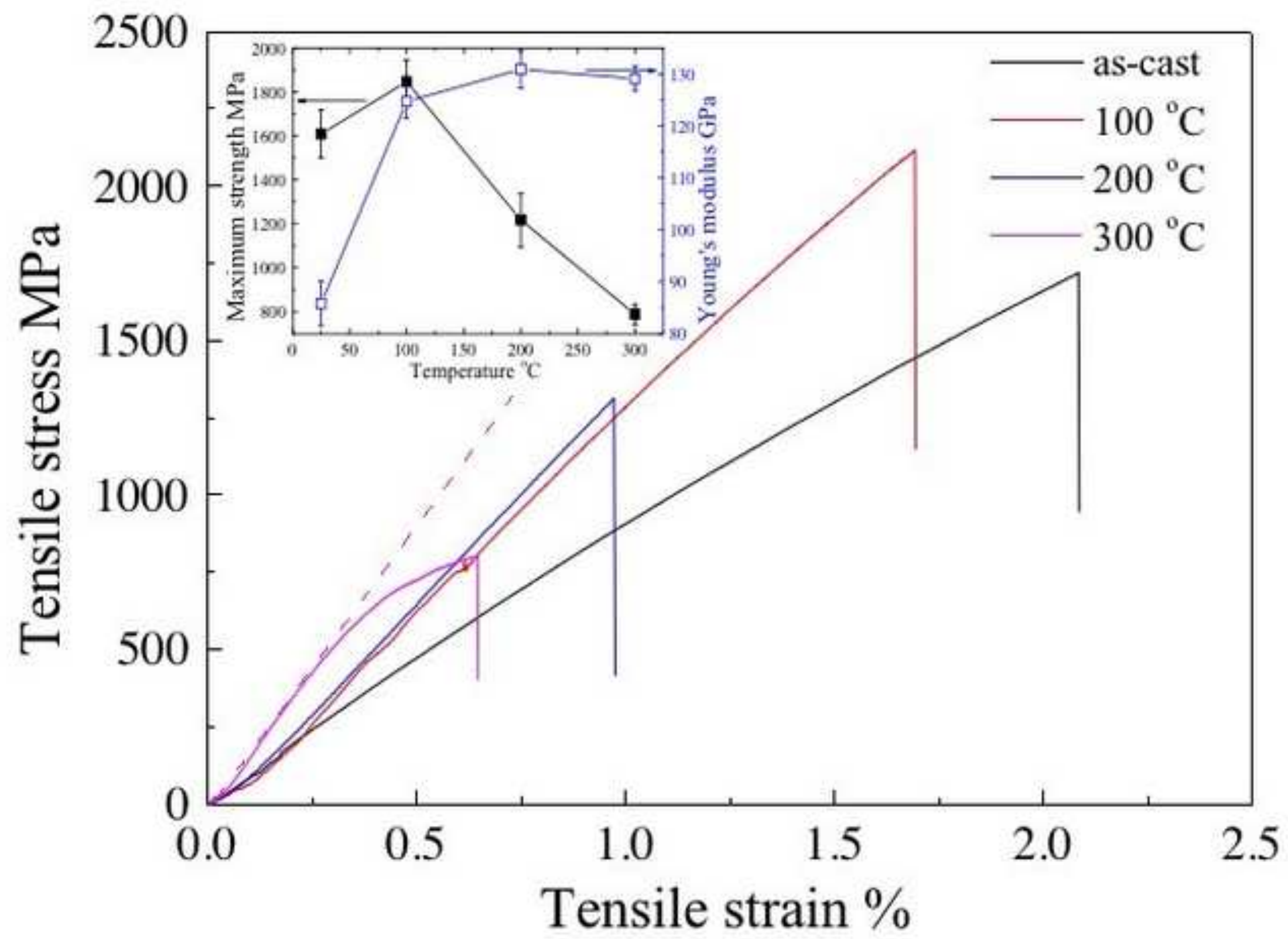



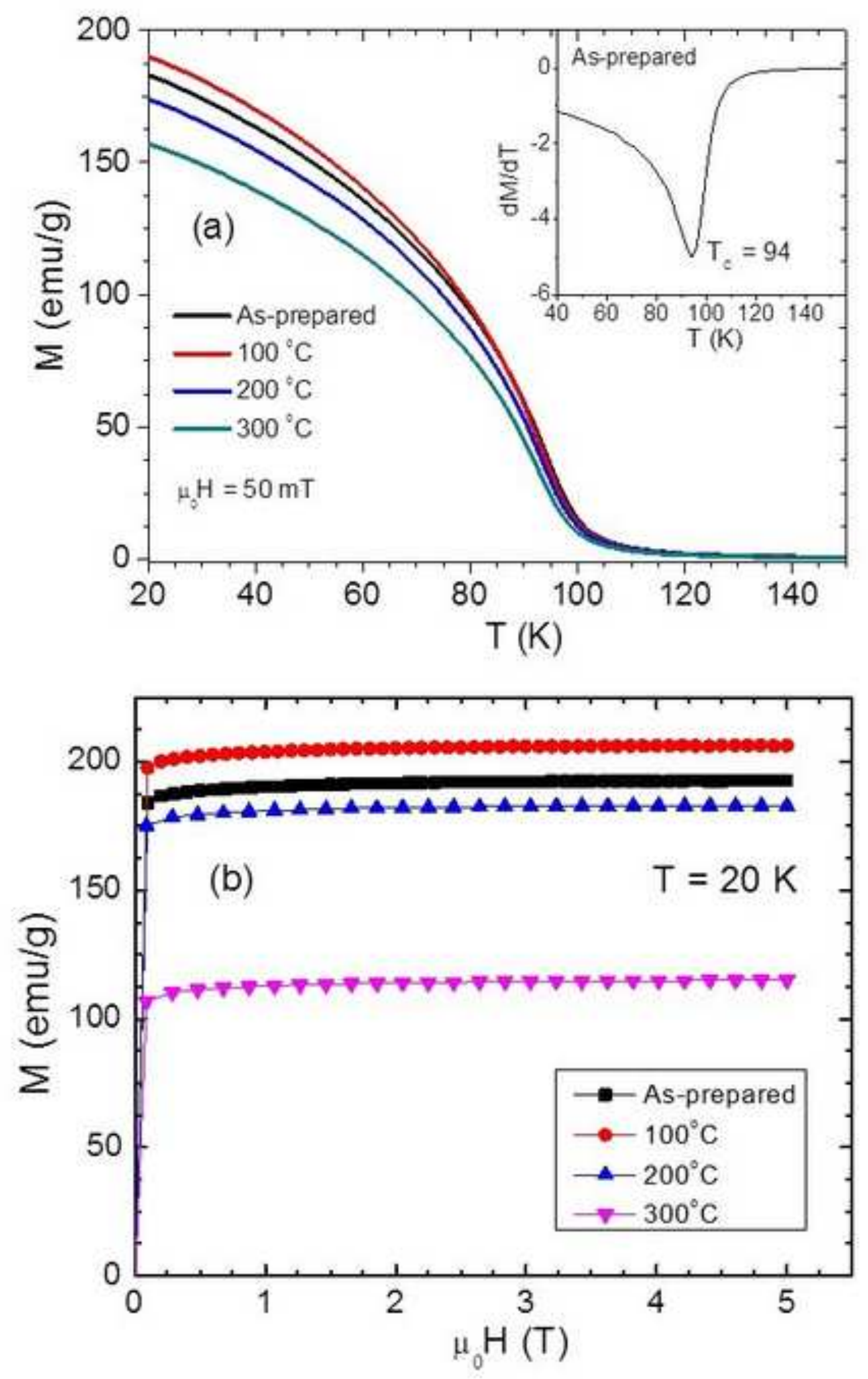

Figure 

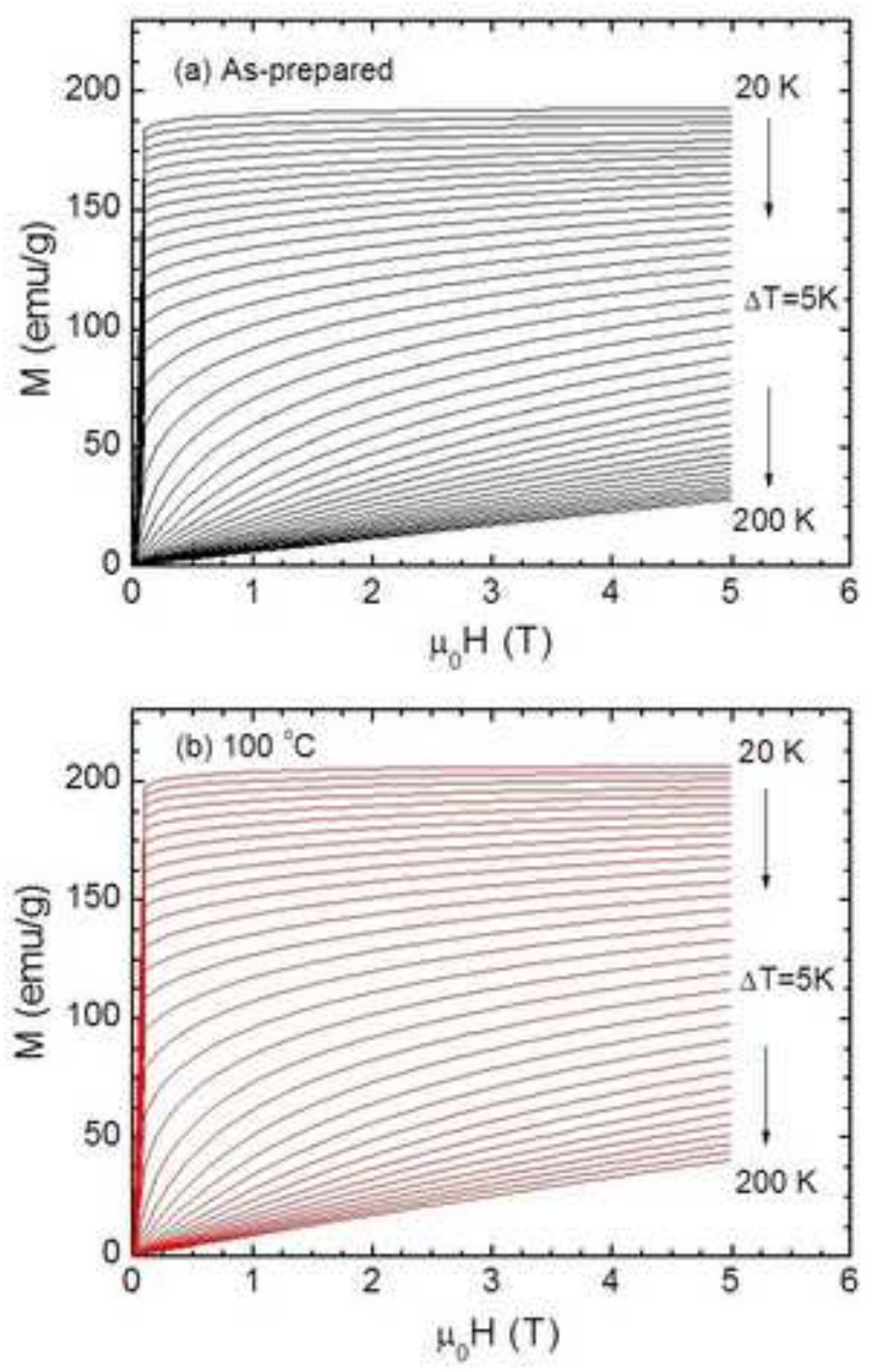

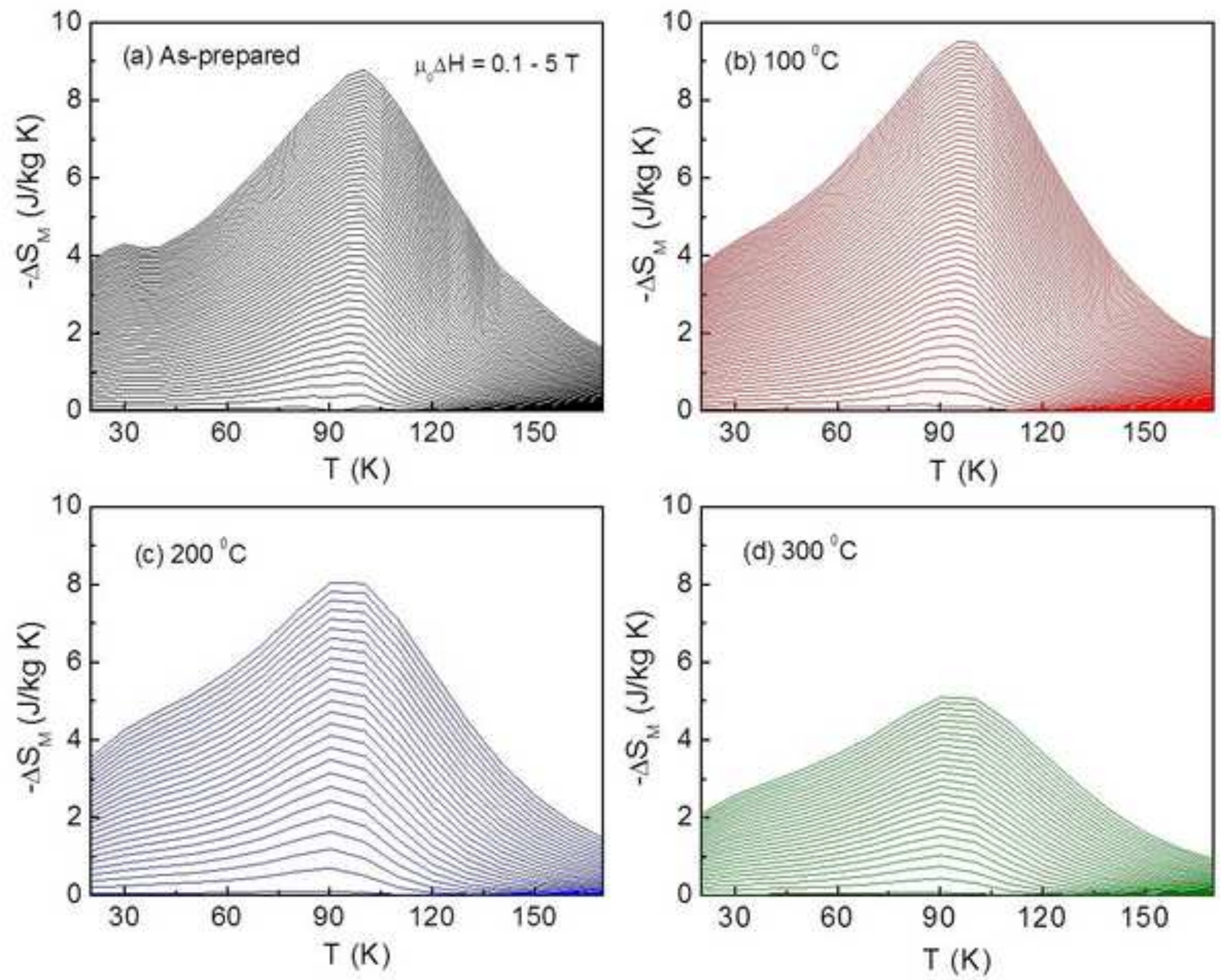